\title{
BMJ Open Migraine, tension-type headache and medication-overuse headache in a large population of shift working nurses: a cross-sectional study in Norway
}

\author{
Bjørn Bjorvatn, ${ }^{1,2}$ Ståle Pallesen, ${ }^{2,3}$ Bente E Moen, ${ }^{1}$ Siri Waage, ${ }^{1,2}$ \\ Espen Saxhaug Kristoffersen ${ }^{4}$
}

To cite: Bjorvatn B, Pallesen S, Moen BE, et al. Migraine, tension-type headache and medicationoveruse headache in a large population of shift working nurses: a cross-sectional study in Norway. BMJ Open 2018;8:e022403. doi:10.1136/ bmjopen-2018-022403

- Prepublication history for this paper is available online. To view these files, please visit the journal online (http://dx.doi org/10.1136/bmjopen-2018022403).

Received 19 February 2018 Revised 22 August 2018 Accepted 20 September 2018

Check for updates

(c) Author(s) (or their employer(s)) 2018. Re-use permitted under CC BY-NC. No commercial re-use. See rights and permissions. Published by BMJ.

${ }^{1}$ Department of Global Public Health and Primary Care, University of Bergen, Bergen, Norway

${ }^{2}$ Norwegian Competence Center for Sleep Disorders, Haukeland University Hospital, Bergen, Norway

${ }^{3}$ Department of Psychosocial Science, University of Bergen, Bergen, Norway

${ }^{4}$ Department of General Practice, University of Oslo, Oslo, Norway

Correspondence to

Dr Bjørn Bjorvatn;

bjorn.bjorvatn@uib.no

\section{ABSTRACT}

Objectives To investigate associations between different types of headaches and shift work.

Design, participants and outcome measures Nurses with different work schedules (day work, two-shift rotation, night work, three-shift rotation) participated in a cohort study with annual surveys that started in 2008/2009. In 2014 (wave 6), a comprehensive headache instrument was included in the survey, in which 1585 nurses participated. Headaches were assessed according to the International Classification of Headache Disorders IIlb. Frequent headache ( $\geq 1$ day per month), migraine, tension-type headache, chronic headache (headache $>14$ days per month) and medication-overuse headache (chronic headache + acuteheadache medication $\geq 10$ days last month) comprised the dependent variables. Adjusted (for sex, age, percentage of full-time equivalent, marital status, children living at home) logistic regression analyses were conducted with work schedule, number of night shifts worked last year, number of quick returns ( $<11$ hours in-between shifts) last year, shift work disorder and insomnia disorder as predictors.

Results Frequent headache, migraine and chronic headache were associated with shift work disorder (OR $2.04,95 \% \mathrm{Cl} 1.62$ to $2.59 ; 1.60,1.21$ to $2.12 ; 2.45,1.25$ to 4.80 , respectively) and insomnia disorder (OR 1.79 , $95 \% \mathrm{Cl} 1.43$ to $2.23 ; 1.55,1.18$ to $2.02 ; 3.03,1.54$ to 5.95 , respectively), but not with work schedule, number of night shifts or number of quick returns. Tension-type headache was only associated with $>20$ night shifts last year (OR 1.41, 95\% $\mathrm{Cl} 1.07$ to 1.86). Medication-overuse headache was only associated with insomnia disorder (OR $7.62,95 \% \mathrm{Cl} 2.48$ to 23.41 ).

Conclusions We did not find any association between different types of headaches and work schedule. However, tension-type headache was associated with high number of night shifts. Nurses with sleep disorders (insomnia disorder and shift work disorder) reported higher prevalence of frequent headaches, migraine, chronic headache and medication-overuse headache (only insomnia) compared with nurses not having insomnia disorder and shift work disorder, respectively.

\section{INTRODUCTION}

Shift work is associated with impaired health, and several studies show that working shifts
Strengths and limitations of this study

- A large and homogeneous sample of nurses with different work schedules.

- Validated questionnaires for diagnosing different types of headaches and sleep disorders

- No clinical interviews by physicians.

- Few nurses with some of the headache subtypes, which limits statistical power in these analyses.

- No conclusions about causality due to the cross-sectional design.

increase the risk of sleep disturbances, cardiovascular disease, metabolic disorders and cancer. ${ }^{1}$ Sleep disturbances are considered to be the most common complaint, especially among rotating shift workers and night workers. ${ }^{23}$ Night workers are on duty during their biological resting phase and are forced to schedule sleep to their biological active phase. This has been proposed as a causative factor for sleep and health problems. ${ }^{1}$ Accordingly, studies suggest that the number of night shifts per year and the number of quick returns (defined at shifts with less than 11 hours in-between) per year are associated with increased risk of health complaints and sick leave. ${ }^{4-7}$

Recently, the focus on shift workers fulfilling the criteria for shift work disorder (SWD) has intensified. ${ }^{8-10}$ SWD is characterised by complaints of sleep problems and excessive sleepiness caused by work schedules overlapping with the habitual time for sleep. ${ }^{811}$ This disorder affects $4.8 \%-44.3 \%$ of nurses depending on type of work schedule. ${ }^{12}$ SWD has been associated with impaired health, for example, depression and hypertension. 8101213

Few studies have specifically investigated the association between shift work and the presence and severity of headache. This 
is somewhat surprising, considering the association between sleep and headache. ${ }^{14-16}$ Many of the existing studies suffer from methodological limitations, such as low number of participants $(<300)^{17-19}$ and not using validated headache questions. ${ }^{17-21}$ One study from China reported that greater number of night shifts is positively associated with prevalence of headache, ${ }^{22}$ and another study from Taiwan suggested that shift work increases the risk of migraine..$^{23} \mathrm{~A}$ Scandinavian study found an association between evening work, but not night work, and migraine. ${ }^{16}$ The relationship between sleep and headache seems to be bidirectional. Lack of sleep can trigger headache, but sleep may also alleviate headache. ${ }^{15}$ Disturbed sleep due to shift work is therefore likely to increase the risk of headache. The most common primary headaches in the general population are migraine and tension-type headache. ${ }^{24}$ Most studies have focused on migraine and shift work, ${ }^{15} 16$ although tension-type headache (TTH) is considered the most common form of headache with an estimated worldwide prevalence of approximately $40 \% .{ }^{24}$ The prevalence of migraine in the general population is $10 \%-16 \% .^{24}{ }^{25}$ Chronic headache is defined as headache occurring more than 14 days per month and is present in $2 \%-4 \%$ of the general population. ${ }^{24-27}$ Medication-overuse headache $(\mathrm{MOH})$ is a condition characterised by chronic headache and overuse of acute headache medications, usually defined as intake of acute pain or migraine medications 10 or more days per month. ${ }^{2628}$ The prevalence of $\mathrm{MOH}$ in the general population is $1 \%-2 \%$, with more females being afflicted than males. ${ }^{28} 29$

As headache is common in the general population and since sleep loss, which often occurs concomitant with shift work, may trigger headache, we aimed to investigate whether different types of headaches (ie, migraine, TTH, chronic headache, $\mathrm{MOH}$ ) were related to work schedules, number of night shifts, number of quick returns, SWD and insomnia disorder. Nurses comprise a large population of shift workers and are thereby suitable for such studies. We hypothesised that nurses involved in night and shift work would report a higher prevalence of headaches compared with day workers.

\section{METHODS}

\section{Procedure and participants}

The data stemmed from the ongoing longitudinal cohort study 'SUrvey of Shift work, Sleep and Health' (SUSSH) among Norwegian nurses. The first data collection was conducted during winter 2008/2009 (wave 1) when a sample of 5400 nurses was randomly selected from the Norwegian Nurses Organisation's membership roll and invited to participate. A total of 2059 (response rate $=38.1 \%$ ) nurses completed the questionnaire at the first wave. In order to increase the study population, an additional sample of 906 newly educated nurses (response rate $=33.1 \%$ ) was recruited in 2009. The total sample in wave 1 therefore included 2965 nurses, see details in Bjorvatn $e t a l^{30}$ The nurses who responded to the first wave have been invited to participate in annual follow-ups by receiving questionnaires sent by postal mail with prepaid envelopes for returning the completed forms. Up to two reminders were sent to nurses who did not respond. The nurses who returned the questionnaire took part in a lottery, in which 25 individuals won a gift card with a value of $500 \mathrm{NOK}(\sim \mathrm{US} \$ 60)$. The present study reports findings based on data from the sixth (2014) wave, in which the headache questionnaire was included. A total of 1991 out of 2869 eligible nurses completed the questionnaire at wave 6 , yielding a response rate of $69.4 \%$. Nurses who reported that they were no longer working as nurses at wave 6 were excluded from the analyses, leaving a total study population of 1585 nurses.

\section{Demographics and work-related factors}

The demographic variables were assessed in wave 6 , except for age and sex that were registered in wave 1 . The nurses responded to questions about marital status (married/ cohabiting; yes/no), children living at home (yes/no), percentage of full-time equivalent $(<50 \%, 50 \%-75 \%$, $76 \%-90 \%$, >90\% position), work schedule (day only, evening only, two-shift rotation (day and evening), night only, three-shift rotation (day, evening and night), and other schedules including night work), number of night shifts worked last year and number of quick returns (defined as less than 11 hours between consecutive work shifts) worked last year. Few nurses worked 'evening only' $(n=6)$ and 'other schedules including night shifts' $(n=67)$, and these shifts were therefore excluded in the analysis of the association between work schedule and headache.

\section{Headache}

The comprehensive headache questionnaire was designed to determine whether the nurses suffered from headache, and fulfilled the International Classification of Headache Disorders (ICHD) IIIb criteria for migraine, tensiontype headache (TTH) and medication-overuse headache $(\mathrm{MOH}) .{ }^{26}$ The nurses were first screened: 'Have you suffered from headache during the last year?' and only nurses who answered 'yes' were asked to respond to the other headache items. The screening-positive headache sufferers were asked to report frequency, attack duration, intensity and accompanying headache symptoms to classify migraine and TTH, accordingly. The diagnoses of migraine and TTH were mutually exclusive. Frequent headache was defined as headache $\geq 1$ day per month, and chronic headache was defined as headache $>14$ days per month, independently of the underlying subtype of headache. $\mathrm{MOH}$ was defined as chronic headache and intake of acute headache medication for $\geq 10$ days the previous month. The questionnaire-based headache diagnoses used here have previously been validated in a large unselected general population sample. ${ }^{25} 3132$

\section{Shift work disorder}

SWD was measured with three previously used questions ${ }^{11} 12$ based on the minimal criteria listed in the second edition 
of the International Classification of Sleep Disorders (ICSD2) ${ }^{33}$ The questions were: (a) Do you experience either difficulties sleeping or experience excessive sleepiness? (yes/ no), (b) Is the sleep or sleepiness problem related to a work schedule that makes you work when you normally would sleep? (yes/no), (c) Have you had this sleep or sleepiness problem related to the work schedule for at least 1 month? (yes/no). Participants were classified as having SWD if they endorsed all three questions.

\section{Insomnia disorder}

Insomnia symptoms were evaluated with Bergen Insomnia Scale (BIS). ${ }^{34}$ The BIS consists of six items, and was developed based on the diagnostic criteria for insomnia according to fourth revision version of the Diagnostic and Statistical Manual for Mental Disorders (DSM-IV-TR). ${ }^{35}$ The items are scored along an eight-point scale indicating the number of days per week for which a specific insomnia symptom is experienced ( $0-7$ days). The items refer to sleep onset (sleep latency exceeding $30 \mathrm{~min}$ ), wake after sleep onset (more than $30 \mathrm{~min}$ ), early morning awakening (more than $30 \mathrm{~min}$ ), non-restorative sleep, daytime impairment and dissatisfaction with sleep. The time frame is insomnia symptoms experienced during the past month. According to DSM- 5 criteria, ${ }^{36}$ insomnia disorder is defined as scoring 3 days per week or more on at least one of the first three items as well as 3 days per week or more on at least one of the latter two items. Missing responses to any of the insomnia questions were treated as not reporting that specific insomnia symptom. The scale has acceptable test-retest reliability, and good convergent and discriminative validity in relation to other self-report measures as well as to polysomnographic data. ${ }^{34}$ Cronbach's alpha for the BIS was 0.83 in the present sample.

\section{Patient and public involvement}

The questionnaire was developed by a group of researchers experienced with shift work and shift work related problems. The participating nurses were not involved in the design, recruitment or conduct of the study. The results will be disseminated to the study participants in the yearly report we send to the journal of the Norwegian nurses. Here we address last year's published data from the cohort study. In addition, the results will appear on a designated website - www.sussh.no (after publication).

\section{Statistics}

The statistical analyses were conducted with IBM SPSS Statistics V.23 for Windows. The prevalence of frequent headache, migraine, TTH, chronic headache and $\mathrm{MOH}$ in relation to the different work schedules, categories of night shifts and quick returns last year, SWD and insomnia disorder were explored by the Pearson chi-square tests (with Yates' correction for continuity when used in a $2 \times 2$ table). In addition, separate adjusted (with sex, age, percentage of full-time equivalent, marital status, children living at home as co-variates) logistic regression analyses were performed to assess different headaches (frequent
Table 1 Characteristics of the Norwegian nurses in the study

\begin{tabular}{|c|c|}
\hline Sex $(n=1578)$ : female & $90.5 \%$ \\
\hline Age in wave $1(n=1583)$ : mean (SD) & $\begin{array}{l}32.5(8.5) \\
\text { years }\end{array}$ \\
\hline \multicolumn{2}{|l|}{ Percentage of full-time equivalent $(n=1536)$ : } \\
\hline$<50 \%$ & $3.9 \%$ \\
\hline $50 \%-75 \%$ & $20.3 \%$ \\
\hline $76 \%-90 \%$ & $16.5 \%$ \\
\hline$>90 \%$ & $59.2 \%$ \\
\hline Married/cohabiting $(n=1582)$ : yes & $76.5 \%$ \\
\hline Children living at home $(n=1578)$ : yes & $63.3 \%$ \\
\hline \multicolumn{2}{|l|}{ Work schedule $(n=1532)$ : } \\
\hline Day only & $19.3 \%$ \\
\hline Evening only & $0.4 \%$ \\
\hline Two-shift rotation & $32.4 \%$ \\
\hline Night shift only & $6.6 \%$ \\
\hline Three-shift rotation & $36.9 \%$ \\
\hline Other schedules including night shifts & $4.4 \%$ \\
\hline \multicolumn{2}{|l|}{ Number of night shifts last year $(n=1534)$ : } \\
\hline 0 night shifts & $39.8 \%$ \\
\hline $1-20$ night shifts & $26.1 \%$ \\
\hline$>20$ night shifts & $34.0 \%$ \\
\hline \multicolumn{2}{|l|}{ Number of quick returns last year $(n=1511)$ : } \\
\hline 0 quick returns & $22.6 \%$ \\
\hline $1-20$ quick returns & $25.2 \%$ \\
\hline$>20$ quick returns & $52.2 \%$ \\
\hline Shift work disorder $(n=1567)$ : yes & $27.3 \%$ \\
\hline Insomnia disorder $(n=1585)$ : yes & $31.7 \%$ \\
\hline Headache last year $(n=1579)$ : yes & $56.0 \%$ \\
\hline $\begin{array}{l}\text { Frequent headache ( } \geq 1 \text { day per month) } \\
(n=1585) \text { : yes }\end{array}$ & $48.1 \%$ \\
\hline Migraine $(n=1537)$ : yes & $19.6 \%$ \\
\hline Tension-type headache $(n=1559)$ : yes & $27.9 \%$ \\
\hline Chronic headache $(n=1577)$ : yes & $2.3 \%$ \\
\hline Medication-overuse headache $(n=1579)$ : yes & $1.2 \%$ \\
\hline
\end{tabular}

$\mathrm{n}$, number of nurses.

headache, migraine, TTH, chronic headache, $\mathrm{MOH}$ ) as dependent variables with work schedule (day only as a reference, compared with two-shift rotation, night only and three-shift rotation), number of night shifts last year $(0,1-20,>20$ night shifts), number of quick returns last year $(0,1-20,>20$ quick returns), SWD and insomnia disorder as predictors. Significance level was set to. 05 .

\section{RESULTS}

Demographic characteristics are presented in table 1 . Most of the nurses were females $(90.5 \%)$ and mean age in wave 1 was 32.5 years $(\mathrm{SD}=8.5)$. Three-shift and two-shift 
Table 2 Prevalence of different types of headache complaints among Norwegian nurses

\begin{tabular}{|c|c|c|c|c|c|}
\hline & $\begin{array}{l}\text { Frequent } \\
\text { headache }^{*}\end{array}$ & Migraine & $\begin{array}{l}\text { Tension-type } \\
\text { headache }\end{array}$ & $\begin{array}{l}\text { Chronic } \\
\text { headache† }\end{array}$ & $\begin{array}{l}\text { Medication-overuse } \\
\text { headache }\end{array}$ \\
\hline & $\%(n)$ & $\%(n)$ & $\%(n)$ & $\%(n)$ & $\%(n)$ \\
\hline Day only & $47.3(140)$ & $22.6(65)$ & $24.5(71)$ & $1.7(5)$ & $1.0(3)$ \\
\hline Two-shift rotation & $48.7(242)$ & $20.3(98)$ & $26.1(129)$ & $3.2(16)$ & $1.6(8)$ \\
\hline Night shift only & $47.5(48)$ & $16.3(16)$ & $29.0(29)$ & $2.0(2)$ & $2.0(2)$ \\
\hline Night shifts last year $(n=1489-1534)$ : & $3.4 \ddagger, p=0.180$ & $3.3 \ddagger, p=0.188$ & $6.9 \ddagger, p=0.032$ & $0.4 \ddagger, p=0.813$ & $1.1 \neq, p=0.578$ \\
\hline 0 night shifts & $47.8(292)$ & $21.9(130)$ & $24.4(147)$ & $2.6(16)$ & $1.5(9)$ \\
\hline $1-20$ night shifts & $44.6(179)$ & $18.0(70)$ & $30.0(118)$ & $2.0(8)$ & $0.8(3)$ \\
\hline$>20$ night shifts & $50.8(265)$ & $18.1(92)$ & $30.9(159)$ & $2.3(12)$ & $1.2(6)$ \\
\hline Quick returns last year $(n=1465-1511)$ : & $0.2 \ddagger, p=0.902$ & $1.5 \ddagger, p=0.480$ & $2.4 \neq, p=0.296$ & $0.2 \ddagger, p=0.885$ & $0.8 \ddagger, p=0.666$ \\
\hline Shift work disorder ( $n=1521-1567)$ : & $36.9 \ddagger, p<0.0005$ & 11.3ł, $p=0.001$ & $1.6 \neq, p=0.208$ & $5.7 \neq, p=0.017$ & $0.5 \neq, p=0.491$ \\
\hline No & $43.4(494)$ & $17.7(197)$ & $26.9(301)$ & $1.8(20)$ & $1.1(12)$ \\
\hline Yes & $60.7(260)$ & $25.6(104)$ & $30.2(127)$ & $4.0(17)$ & $1.6(7)$ \\
\hline Insomnia disorder $(n=1537-1585)$ : & $25.1 \neq, p<0.0005$ & $10.1 \neq, p=0.001$ & $0.0 \neq, p=0.983$ & $9.7 \neq, p=0.002$ & $15.6 \ddagger, p<0.0005$ \\
\hline No & $43.8(474)$ & $17.4(184)$ & $28.0(297)$ & $1.5(16)$ & $0.5(5)$ \\
\hline Yes & $57.5(289)$ & $24.5(118)$ & $27.8(138)$ & $4.2(21)$ & $2.8(14)$ \\
\hline
\end{tabular}

Significant findings are shown in bold.

*Headache $\geq 1$ days per month.

†Headache $>14$ days per month.

$\ddagger$ Pearson $\mathrm{X}^{2}$, with Yates' correction for continuity when used in a $2 \times 2$ table.

rotation were the most common work schedules (table 1$)$. Mean number of night shifts last year was $23.5(\mathrm{SD}=36.7)$ and mean number of quick returns last year was 33.4 $(\mathrm{SD}=35.4)$. Shift work disorder and insomnia disorder were present in $27.3 \%$ and $31.7 \%$ of the nurses, respectively. In total, $56.0 \%$ of the nurses $(n=885)$ reported headache complaints during the last year, and $48.1 \%(\mathrm{n}=763)$ frequent headache ( $\geq 1$ day per month). Migraine, TTH, chronic headache and MOH were present in $19.6 \%$ $(\mathrm{n}=302), 27.9 \%(\mathrm{n}=435), 2.3 \%(\mathrm{n}=37)$, and $1.2 \%(\mathrm{n}=19)$ of the total sample of nurses, respectively (table 1 ).

We did not find any significant differences between the prevalence of frequent headache, migraine, TTH, chronic headache or $\mathrm{MOH}$ across work schedules (table 2). Similarly, logistic regression analyses with adjustment for sex, age, percentage of full-time equivalent, marital status and children living at home revealed no association between the different headache types and work schedule (table 3).

The prevalence of TTH was higher in nurses working night shifts last year compared with those not working night shifts, but we found no association between frequent headache, migraine, chronic headache or $\mathrm{MOH}$ and number of night shifts last year (table 2). Similarly, in the adjusted logistic regression analysis, TTH was significantly associated with $>20$ night shifts last year (OR 1.41, 95\% CI 1.07 to 1.86 ) (table 3 ). There were no associations between the different headache types and number of quick returns last year (tables 2 and 3).

The prevalence of frequent headache, migraine and chronic headache were all clearly higher among nurses with SWD compared with nurses without SWD (table 2). Furthermore, adjusted logistic regression analyses revealed that frequent headache, migraine and chronic headache all were significantly associated with SWD, with ORs 2.04, 95\%CI 1.62 to 2.59; 1.60, 1.21-2.12; 2.45, $1.25-4.80$, respectively (table 3 ). TTH and $\mathrm{MOH}$ were not significantly associated with SWD (tables 2 and 3).

The prevalence of frequent headache, migraine, chronic headache and $\mathrm{MOH}$ were all clearly higher among nurses with insomnia disorder compared with nurses without insomnia disorder (table 2). These findings were also present in the adjusted logistic regression analyses, with OR $1.79,95 \%$ CI 1.43 to 2.23 ; 1.55 , 1.18 to $2.02 ; 3.03,1.54$ to $5.95,7.62,2.48$ to 23.41 , respectively (table 3 ). The only headache type that was not associated with insomnia disorder was TTH (tables 2 and 3).

\section{DISCUSSION}

The present study showed that nurses with different work schedules reported similar prevalence of frequent headache, migraine, TTH, chronic headache and $\mathrm{MOH}$. 
Table 3 Separate adjusted logistic regression analyses with different headache types as the dependent variables among Norwegian nurses

\begin{tabular}{|c|c|c|c|c|c|}
\hline & Frequent headache* & Migraine & $\begin{array}{l}\text { Tension-type } \\
\text { headache }\end{array}$ & Chronic headache & $\begin{array}{l}\text { Medication-overuse } \\
\text { headache }\end{array}$ \\
\hline Independent variables & $\begin{array}{l}\text { OR }(95 \% \text { Cl)† } \\
n=1439-1519\end{array}$ & $\begin{array}{l}\text { OR }(95 \% \text { Cl)† } \\
n=1398-1476\end{array}$ & $\begin{array}{l}\text { OR }(95 \% \text { Cl)† } \\
n=1416-1495\end{array}$ & $\begin{array}{l}\text { OR }(95 \% \text { Cl)† } \\
n=1432-1512\end{array}$ & $\begin{array}{l}\text { OR }(95 \% C l) \dagger \\
n=1434-1514\end{array}$ \\
\hline Day only & 1 & 1 & 1 & 1 & 1 \\
\hline Two-shift & 1.07 (0.80 to 1.44 ) & 0.89 (0.62 to 1.28$)$ & 1.11 (0.79 to 1.57$)$ & 1.91 (0.68 to 5.32 ) & 1.49 (0.39 to 5.80$)$ \\
\hline \multicolumn{6}{|l|}{ Number of night shifts } \\
\hline 0 night shifts & 1 & 1 & 1 & 1 & 1 \\
\hline $1-20$ night shifts & 0.86 (0.66 to 1.11$)$ & 0.78 (0.56 to 1.09$)$ & 1.27 (0.95 to 1.70$)$ & $0.73(0.30$ to 1.74$)$ & 0.51 (0.14 to 1.95$)$ \\
\hline$>20$ night shifts & 1.15 (0.90 to 1.47$)$ & 0.80 (0.58 to 1.09$)$ & 1.41 (1.07 to 1.86$)$ & 0.82 (0.38 to 1.80$)$ & 0.78 (0.27 to 2.29$)$ \\
\hline \multicolumn{6}{|l|}{ Shift work disorder } \\
\hline No & 1 & 1 & 1 & 1 & 1 \\
\hline Yes & 2.04 (1.62 to 2.59 ) & 1.60 (1.21 to 2.12$)$ & 1.19 (0.92 to 1.54$)$ & 2.45 (1.25 to 4.80$)$ & 1.67 (0.64 to 4.40$)$ \\
\hline \multicolumn{6}{|l|}{ Insomnia disorder } \\
\hline No & 1 & 1 & 1 & 1 & 1 \\
\hline Yes & 1.79 (1.43 to 2.23$)$ & 1.55 (1.18 to 2.02$)$ & 1.01 (0.79 to 1.29$)$ & 3.03 (1.54 to 5.95$)$ & 7.62 (2.48 to 23.41$)$ \\
\hline
\end{tabular}

Significant findings are shown in bold.

*Headache $\geq 1$ days per month.

†Separate logistic regression analyses for each independent variable with adjustment for sex, age, percentage of full-time equivalent, marital status, and children living at home.

†Headache $>14$ days per month.

These findings did thus not support our hypothesis that shift working nurses would report higher prevalence of headaches than day workers. However, nurses with high number of night shifts during the last year reported higher prevalence of TTH than nurses with no night shifts. Furthermore, nurses with SWD and insomnia disorder reported higher prevalence of most types of headaches compared with nurses without SWD and insomnia disorder, respectively.

We hypothesised that night and shift work would be associated with higher prevalence of headaches. This was based on the well-known association between lack of sleep and headache. ${ }^{1537}$ It is well known that both rotating shift work schedules and night work normally will cause circadian rhythm misalignment and sleep deprivation. ${ }^{98}{ }^{39}$ In line with this, a Chinese study showed that number of night shifts was positively associated with prevalence of different types of headaches. ${ }^{22}$ However, a recent Danish study did not find any association between treatment-seeking migraine and night work or variable working hours. ${ }^{16}$ In the latter study, only fixed evening work was found to be associated (positively) with migraine. One possible explanation for the lack of association between headaches and work schedules in the present study may be the 'healthy shift worker effect'. This is based on the assumption that shift workers have better health than those who avoid or quit shift work. ${ }^{40}$ Hence, nurses with headaches may be more reluctant to work in shifts or quit shift work more frequently than others, leading to underestimates of the possible negative effects of shift work in studies like the present one.

Similarly, the number of night shifts worked the last year was not associated with frequent headache, migraine, chronic headache or MOH. However, TTH was associated with high number of night shifts. This finding suggests that there may be different sleep-headache mechanisms in TTH than in for example, migraine. ${ }^{41}$ In line with this, a polysomnography study found that TTH patients need more sleep than healthy controls, and that inadequate sleep may contribute to increased pain sensitivity in TTH. ${ }^{42}$ Furthermore, a high number of night shifts may not necessarily only cause sleep deprivation, but may also be experienced as stressful and thereby precipitate TTH. High work stress is a risk factor for primary headaches, especially tension-type headache. ${ }^{22}{ }^{43}$ Whether circadian misalignment in itself (often occurring among shift and night workers) triggers headaches is not known, and this topic should receive more attention in the future.

Many Norwegian nurses with rotating shift schedules have quick returns (defined as shifts separated by less than 11 hours) in their roster. For the nurses, most quick returns involve working an evening shift followed by a day shift. Such short rest in-between shifts typically cause sleep 
deprivation and health problems. ${ }^{45}$ However, we found no association between headaches and quick returns. This was surprising and may suggest that short-term sleep deprivation, as seen with quick returns, may not pose a major problem in relation to headache risk. This lack of association was found even though a high percentage of nurses reported frequent quick returns.

In the present study, frequent headache, migraine and chronic headache were all associated with SWD. These novel findings suggest that nurses who do not cope well with shift work are at increased risk of other health complaints like headaches. However, our study cannot say anything about cause-and-effect. That is, it may be that headache increases the risk of SWD. Future studies should consequently focus on whether there may be common vulnerability factors (eg, genetic, health behaviour, etc.) between headaches and sleep-related disorders. Interestingly and surprisingly, TTH was not associated with SWD, suggesting that different pathophysiological mechanisms may be involved across the different types of headaches. This issue warrants further studies.

Insomnia disorder was associated with frequent headache, migraine, chronic headache and $\mathrm{MOH}$, which is in line with the findings from several other studies. ${ }^{15445}$ However, few studies have used formal diagnostic criteria for insomnia disorder, like the present study. Thus, one major asset with the present study was the use of ICSD and ICHD criteria for sleep disorders and headache classification, respectively. Surprisingly, TTH was not associated with insomnia disorder in our study, in contrast to two other population-based studies. ${ }^{3746}$ However, none of those studies used the formal diagnostic criteria for insomnia disorder. Lack of association between insomnia disorder and TTH may be related to methodological limitations, but suggests the need for more research, and especially studies with a longitudinal design. $\mathrm{MOH}$ was significantly associated with insomnia disorder, but not with any of the work-related variables. In fact, our data indicate that nurses with insomnia disorder had more than seven times higher risk of $\mathrm{MOH}$ than those without insomnia disorder. This strong association warrants further studies.

\section{Strengths and limitations of this study}

The present study was based on a large and homogeneous sample of nurses that limits the influence from possible confounding variables. Other strengths were the use of validated headache diagnoses and a validated insomnia scale as well as criteria-based SWD diagnostics. Furthermore, the study did not have a primary focus on headache, it was one of many health outcomes. Thus, a possible selection bias related to headache was unlikely. In terms of limitations, it should be noted that the response rate in the first wave was low, which may make the interpretation of the data and conclusions less generalisable. Still, the response rate in wave 6 where the headache questionnaire was included was high. Due to the high number of participants in our survey, it was not feasible to apply the gold standard, ie, a clinical interview by a physician experienced in headache and sleep diagnostics.
For the same reason, prospective headache and sleep diaries were not feasible. However, the questionnaire-based headache diagnostic procedures have been included in several previous large population-based studies and have been validated against clinical interviews with a high degree of agreement. ${ }^{253132}$ A limitation of the headache questionnaire is that migraine and TTH are mutually exclusive, that is, the questionnaire only allows the participant to be diagnosed with the most bothersome headache subtype even though some might suffer from both migraine and $\mathrm{TTH} .{ }^{25}$ It is possible that differences between migraine and TTH are underestimated owing to the presence of people with TTH in the migraine group and vice versa, making the two groups more similar than they actually are. Thus, some caution is needed when interpreting the results. As migraine is hierarchically more important in the headache classification ${ }^{26}$ than TTH, it is possible that there is an underestimation of TTH in the sample. However, the prevalence of the different headaches reported in the present study is similar to those reported previously, ${ }^{24} 252729$ strengthening the assumption of representativeness of the study population. The number of participants with chronic headache and $\mathrm{MOH}$ were low, limiting the statistical power in these analyses. In the logistic regressions we adjusted for several relevant confounders, like sex, age, percentage of full-time equivalent, marital status and children living at home, because such factors are known to influence shift work tolerance and headache. ${ }^{12}{ }^{21}$ However, other possible and relevant factors were not adjusted for, for example, physical inactivity, stress and psychological disturbances, ${ }^{1421}$ since data on these variables were not available. Lack of such adjustment should be taken into consideration when interpreting the results. Finally, it should be noted that the cross-sectional design does not permit any conclusions about causality in the relationship between headaches and work variables.

\section{CONCLUSION}

We found a significant association between headaches and SWD and insomnia disorder in our cohort of nurses. In fact, nurses with SWD reported higher prevalence of frequent headache, migraine and chronic headache compared with nurses not having SWD. Similarly, nurses with insomnia disorder, compared with those without, reported higher prevalence of all types of headache, except TTH. Although we did not find any association between different types of headaches and work schedule or quick returns, TTH was associated with a high number of night shifts. Future longitudinal research should be conducted in order to investigate the causality/directionality of association between headaches and work variables.

Contributors BB contributed to the design of the study, data collection, data analysis, drafted the paper and approved the final version. SP, BEM and SW contributed to the design of the study, data collection, data analysis, revised the paper and approved the final version. ESK contributed to the design of the study, data analysis, revised the paper and approved the final version.

Funding The study received a grant for practical administration and data collection from the Western Norway Regional Health Authority (grant number 911386, no 
personal payment/salary). The Norwegian Nurses Organisation has provided grants to cover some of the the running expenses of the SUSSH study. The study was further partly funded from Nordforsk, Nordic Program on Health and Welfare (74809).

\section{Competing interests None declared.}

Patient consent Obtained.

Ethics approval The Regional Committee for Medical and Health Research Ethics of Western Norway (REK-West, no 088.08).

Provenance and peer review Not commissioned; externally peer reviewed.

Data sharing statement № additional data available.

Open access This is an open access article distributed in accordance with the Creative Commons Attribution Non Commercial (CC BY-NC 4.0) license, which permits others to distribute, remix, adapt, build upon this work non-commercially, and license their derivative works on different terms, provided the original work is properly cited, appropriate credit is given, any changes made indicated, and the use is non-commercial. See: http://creativecommons.org/licenses/by-nc/4.0/.

\section{REFERENCES}

1. Kecklund G, Axelsson J. Health consequences of shift work and insufficient sleep. BMJ 2016;355:i5210.

2. Akerstedt T. Shift work and disturbed sleep/wakefulness. Occup Med 2003;53:89-94.

3. Øyane NM, Pallesen S, Moen BE, et al. Associations between night work and anxiety, depression, insomnia, sleepiness and fatigue in a sample of Norwegian nurses. PLoS One 2013;8:e70228.

4. Eldevik MF, Flo E, Moen BE, et al. Insomnia, excessive sleepiness, excessive fatigue, anxiety, depression and shift work disorder in nurses having less than 11 hours in-between shifts. PLoS One 2013;8:e70882.

5. Vedaa Ø, Pallesen $S$, Waage $S$, et al. Short rest between shift intervals increases the risk of sick leave: a prospective registry study. Occup Environ Med 2017;74:496-501.

6. Flo E, Pallesen S, Moen BE, et al. Short rest periods between work shifts predict sleep and health problems in nurses at 1-year followup. Occup Environ Med 2014;71:555-61.

7. Ferri $\mathrm{P}$, Guadi M, Marcheselli L, et al. The impact of shift work on the psychological and physical health of nurses in a general hospital: a comparison between rotating night shifts and day shifts. Risk Manag Healthc Policy 2016:9:203-11.

8. Di Milia L, Waage S, Pallesen S, et al. Shift work disorder in a random population sample--prevalence and comorbidities. PLoS One 2013;8:e55306.

9. Wright KP, Bogan RK, Wyatt JK. Shift work and the assessment and management of shift work disorder (SWD). Sleep Med Rev 2013;17:41-54

10. Waage S, Pallesen S, Moen BE, et al. Predictors of shift work disorder among nurses: a longitudinal study. Sleep Med 2014;15:1449-55

11. Waage S, Moen BE, Pallesen S, et al. Shift work disorder among oil rig workers in the North Sea. Sleep 2009;32:558-65.

12. Flo E, Pallesen S, Magerøy N, et al. Shift work disorder in nurses-assessment, prevalence and related health problems. PLoS One 2012;7:e33981.

13. Drake CL, Roehrs T, Richardson G, et al. Shift work sleep disorder: prevalence and consequences beyond that of symptomatic day workers. Sleep 2004;27:1453-62.

14. Houle TT, Butschek RA, Turner DP, et al. Stress and sleep duration predict headache severity in chronic headache sufferers. Pain 2012;153:2432-40.

15. Kim J, Cho SJ, Kim WJ, et al. Insufficient sleep is prevalent among migraineurs: a population-based study. J Headache Pain 2017;18:50.

16. Jakobsen GS, Timm AM, Hansen ÅM, et al. The association between shift work and treatment-seeking migraine in Denmark. Ergonomics 2017;60:1207-17.

17. Alfredsson L, Akerstedt T, Mattsson M, et al. Self-reported health and well-being amongst night security guards: a comparison with the working population. Ergonomics 1991;34:525-30.

18. Portela LF, Rotenberg L, Waissmann W. Self-reported health and sleep complaints among nursing personnel working under $12 \mathrm{~h}$ night and day shifts. Chronobiol Int 2004;21:859-70

19. Jensen HI, Larsen JW, Thomsen TD. The impact of shift work on intensive care nurses' lives outside work: A cross-sectional study. J Clin Nurs 2018;27:e703-e709.
20. Ho KH, Benjamin KC. Perceived headache associations in Singapore: results of a randomized national survey. Headache 2001;41:164-70

21. Molarius A, Tegelberg A, Ohrvik J. Socio-economic factors, lifestyle, and headache disorders - a population-based study in Sweden. Headache 2008;48:1426-37.

22. Wang $\mathrm{Y}, \mathrm{Xie} \mathrm{J}$, Yang $\mathrm{F}$, et al. The prevalence of primary headache disorders and their associated factors among nursing staff in North China. J Headache Pain 2015;16:4.

23. Kuo WY, Huang CC, Weng SF, et al. Higher migraine risk in healthcare professionals than in general population: a nationwide population-based cohort study in Taiwan. J Headache Pain 2015;16:102

24. Jensen R, Stovner LJ. Epidemiology and comorbidity of headache. Lancet Neurol 2008;7:354-61.

25. Linde M, Stovner LJ, Zwart JA, et al. Time trends in the prevalence of headache disorders. The Nord-Trondelag Health Studies (HUNT 2 and HUNT 3). Cephalalgia 2011;31:585-96

26. Headache Classification Committee of the International Headache Society (IHS). The International Classification of Headache Disorders, 3rd edition (beta version). Cephalalgia 2013;33:629-808.

27. Grande RB, Aaseth K, Gulbrandsen P, et al. Prevalence of primary chronic headache in a population-based sample of 30- to 44-year-old persons. The Akershus study of chronic headache. Neuroepidemiology 2008;30:76-83.

28. Diener HC, Holle D, Solbach K, et al. Medication-overuse headache: risk factors, pathophysiology and management. Nat Rev Neurol 2016;12:575-83.

29. Jonsson P, Hedenrud T, Linde M. Epidemiology of medication overuse headache in the general Swedish population. Cephalalgia 2011;31:1015-22.

30. Bjorvatn B, Magerøy N, Moen BE, et al. Parasomnias are more frequent in shift workers than in day workers. Chronobiol Int 2015;32:1352-8

31. Hagen $\mathrm{K}, \mathrm{Z}$ wart JA, Aamodt $\mathrm{AH}$, et al. The validity of questionnairebased diagnoses: the third Nord-Trøndelag Health Study 2006-2008. $J$ Headache Pain 2010;11:67-73.

32. Hagen K, Zwart JA, Aamodt AH, et al. A face-to-face interview of participants in HUNT 3: the impact of the screening question on headache prevalence. J Headache Pain 2008;9:289-94.

33. American Academy of Sleep Medicine. The international classification of sleep disorders. In: Diagnostic and coding manual. 2nd edn. Westchester, IL, 2005.

34. Pallesen S, Bjorvatn B, Nordhus IH, et al. A new scale for measuring insomnia: the Bergen Insomnia Scale. Percept Mot Skills 2008;107:691-706.

35. American Psychiatric Association. Diagnostic and statistical manual of mental disorders. Text revision (DSM-IV-TR). Washington, DC: American Psychiatric Association, 2000.

36. American Psychiatric Association. Diagnostic and Statistical Manual of Mental Disorders (DSM-5). Washington, DC: American Psychiatric Association, 2013

37. Ødegård SS, Engstrøm M, Sand T, et al. Associations between sleep disturbance and primary headaches: the third Nord-Trøndelag Health Study. J Headache Pain 2010;11:197-206.

38. Bjorvatn B, Pallesen S. A practical approach to circadian rhythm sleep disorders. Sleep Med Rev 2009;13:47-60.

39. Sack RL, Auckley D, Auger RR, et al. Circadian rhythm sleep disorders: part I, basic principles, shift work and jet lag disorders. An American Academy of Sleep Medicine review. Sleep 2007;30:1460-83.

40. Knutsson A. Methodological aspects of shift-work research. Chronobiol Int 2004;21:1037-47.

41. Rains JC, Davis RE, Smitherman TA. Tension-type headache and sleep. Curr Neurol Neurosci Rep 2015;15:520.

42. Engstrøm M, Hagen K, Bjørk M, et al. Sleep quality, arousal and pain thresholds in tension-type headache: a blinded controlled polysomnographic study. Cephalalgia 2014;34:455-63.

43. Bendtsen L, Jensen R. Treating tension-type headache -- an expert opinion. Expert Opin Pharmacother 2011;12:1099-109.

44. Tran DP, Spierings EL. Headache and insomnia: their relation reviewed. Cranio 2013;31:165-70.

45. Uhlig BL, Engstrøm M, Ødegård SS, et al. Headache and insomnia in population-based epidemiological studies. Cephalalgia 2014:34:745-51.

46. Rasmussen BK. Migraine and tension-type headache in a general population: precipitating factors, female hormones, sleep pattern and relation to lifestyle. Pain 1993;53:65-72. 